\title{
FUTURO Y FUTURIDAD
}

Entre los profundos cambios lingüisticos realizados en el latín vulgar, Karl Vossler ha destacado el ocaso de los futuros latinos en -bo y -am como el acontecimiento "de mayores consecuencias". Este proceso y la génesis e historia del futuro románico han suscitado discusiones particularmente vivas. Me referiré aqui a algunos puntos metodológicamente sintomáticos de este debate.

dabo y daré

Ill llamar "futuro" a las formas daré, darás, ctc., es, como se sabe, una abstracción o reducción en un doble sentido, ya que estas formas no se limitan a significar lo futuro, la futuridad de una acción o de un acontecimiento, ni tienen el monopolio de representar tal futuridad.

Esta abstracción corresponde a la perspectiva de la gramática tradicional, cuyo objetivo primordial es catalogar y sistematizar los morfemas y sintagmas del idioma. Los gramáticos renacentistas, al querer "reduzir en artificion la lengua materna, se orientan por sus modelos latinos. Si han encontrado la "maior dificultad" precisamente en adaptar a la propia lengua el esquema de la conjugación latina, el caso del futuro tenía una solución relativamente fácil. Como el español, italiano, francés, portugués poseían una forma "sintética" del tipo daré/darò/donnerai/darei, de función idéntica o semejante a los futuros latinos dabo, legan, etc., aquel tipo románico ("tiempo venidero", Nebrija; "tempo che ha da venire", Trissino) sustituye simplemente, en el paradigma verbal, a los futuros de la gramática latina ${ }^{1}$.

La gramática histórica continúa con esta perspectiva formal, morfológica de la gramática sincrónica. El primer codificador de una lengua vulgar fue también el primero que reconoció el origen perifrástico, analítico del futuro románico: «E 1 venidero del indicativo dizese por rodeo

1. L. KUKENIEIM, Contributions d l'histoire de la grammaire italienne, espagnole et française d l'epoque de la Renaissance, 1932, p. 135. 
del presente del infinitivo $\mathrm{i}$ del presente del indicativo deste verbo [aver] $e$ as, $\mathrm{i}$ assi dezinos io amare (amaré) como si dixessemos io $e$ de aman ${ }^{1}$. La gramática histórica, más tarde, concluye que, a formas sintéticas como dabo, legam, sigue otra perifrástica de infinitivo + habeo que, a su vez, se cristaliza en el tipo amaré, de manera que también históricamente el futuro con habco "sustituyó» al futuro latino. Iista concepción lineal de la evolución tiene una validez limitada y conviene esclarecerla por una comparación. Un individuo puede sustituir a otro como portero de un hotel, como empleado de una empresa, como ministro, pero nunca como individuo, como persona, porque ésta no se limita a ser portero, empleado o ministro. La gramática formal, sincrónica e histórica, no enfoca las unidades morfológicas y sintácticas como individuos irreemplazables, sino como formas de una sola función y, por lo tanto, sustituibles; atribuye, al mismo tiempo, a cada función una forma que la representa. Sólo visto en esta perspectiva de la gramática formal, se puede decir que el tipo daré sustituyó, en gran parte de la Romania, a los futuros sintéticos latinos.

I,os términos suslitución, remplaccment, Ersalz, tan abundantemente cmpleados en la discusión sobre el futuro, pierden su sentido desde que las expresiones de la futuridad se consideran como individuos que colaboran entre ellas para representar la futuridad, $y$, con otras, para cumplir otras tareas.

\section{Expresiones de la futuridad}

El hombre se acerca a lo futuro con su conocimiento de las leyes naturales, con su experiencia o con sus intenciones de actuar o de hacer actuar en el tiempo por venir. Predispone de lo futuro. ya pronosticando, ya planeando. Asi, toda expresión de futuridad tiene, en el fondo y por naturaleza, un carácter condicional:

el tren llegará a las $\mathcal{S}, 30$ (es decir: si podemos confiar en el horario/ si no interviene cualquier cosa extraordinaria, imprevista/ si llega a la hora que ha llegado regularmente/si Dios quiere...), carácter dependiente:

él lo hará (es decir: pienso/calculo/supongo/espero/deseo o temo que, confío en que...),

y carácter modal:

mañana hará mucho sol (es decir: es probable que/puede hacer/debe de hacer/parece que...)

1 ANTonio de NebrijA, Gram. cast., Madrid, I946, pp. I, II5, I25. 
que puede llegar a excluir el sentido temporal de futuro:

él tendrá unos 50 años (= calculando, por su aspecto o por su curriculum, llego al resultado de que él debe de tener...);

ite vas a cacr! (temo que.../te advierto que puedes caer/ino te caigas!). Cuanto mayor sea la previsibilidad, tanto más el futuro se aproxima a expresar la pura temporalidad: mañana cl sol saldrá a las 5,36; todos morircmos un dialtodos hemos de morir (diferente de: todos morircmos aqui/en esta batalla).

Objetivamente, es muy reducido, casi una simple abstracción, el campo de la temporalidad pura, de la futuridad pura, encerrado por los de la probabilidad, la posibilidad, la intención, la persuasión, etc. Subjetivamente, nos moveremos tanto más en el recinto de la pura temporalidad cuanto más confiemos en la realización de nuestros cálculos, de nuestras previsiones, de nuestras intenciones. El futuro es el tiempo gramatical preferido de los visionarios, los pronosticadores y las personas imperiosas.

$\Lambda$ la gama de significados (que réne cl campos scmántico de la futuridad corresponden, por un lado, las variaciones de cntonación que matizan semánticamente una misma forma:

se lo dirélvoy a decirsclo (articulado en tono de promesa, de amenaza, de resolución enérgica, de indecisión...), por otro lado, la gama de diferentes expresiones de la futuridad.

Se conoce la multiplicidad de expresiones de que el latín disponía en este campo 1: en el diálogo cotidiano, el presente de futuridad (pracsens pro futuro), frecuentemente acompañado por un adverbio temporal, ocupa un lugar importante en todas las épocas de la lengua, sobre todo para la primera persona. En el nonólogo, al contrario, y en contextos más solemnes, se prefiere el futuro. Junto con otras formas verbales como el futuro exacto (légero) y las construcciones participiales (lcctulrus sum/legens ero 'estaré leyendo'), una serie de perifrasis evocaba lo futuro con matices semánticos más o menos diferenciados: dare habeol habeo dare/habeo ad dare/habeo de dare, esse/stare ad/per + inf., venire ad + inf., velle/deberc/posse + inf., y otras más.

Todas estas formas son expresiones "nnormales» de la futuridad o de aspectos varios de la futuridad, y hay que deshacerse de la idea, sugerida por Thielmann y sus seguidores, de que hayan sido inventadas o emplea-

1 Pir. Tumbimann, Arch. f. lat. Lex. u. Gramm., I885, II, pp. 48 ss., I 57 ss.;

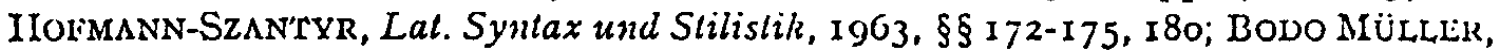
$R F$, s 964, LXXVI, p. 44 ss. 
das para sustituir el futuro, como "Ersatz des Futurs»" ${ }^{1}$. En I894 este principio problemático de atribuir a cada lengua o dialecto una sola expresión de futuridad propiamente dicha, llevó a Meyer-I tübke a construir una sucesión cronológica de las perffrasis latinas mencionadas, sucesión que se reflejaría en su expansión geográfica en la Romania medieval y moderna: r. ${ }^{\circ}$ cantare habco (con orden de palabras latino: Francia, España, Portugal, Italia Central, ues decir, las lenguas literarias más importantes»); 2. habeo cantare (orden de palabras románico: español antiguo, asturiano, portugués, textos medievales del norte de Italia); $3 .^{\circ}$ cantare volo/ volo cantare (Rumania); $4 .^{\circ}$ habeo ad cantare (rumano antiguo, sardo); $5 .^{\circ}$ debeo cantare (logudorés); $6.0^{\circ}$ venio ad cantare (sobreselvano) ${ }^{2}$. Restos de esta teoria, abandonada pronto por el mismo Meyer-Lübke, aparecen todavía en los trabajos más recientes.

Hay que tomar otro punto de partida: entre las expresiones latinas mencionadas, el que hablaba o escribía elegía (con diferencias de época, evidentemente, y en el habla, probablemente, con diferencias regionales) según el carácter y la intención de su comunicación, según la capa social o estilística del idioma en la cual integraba la comunicación. Cuando en el lenguaje hablado el futuro usintéticon dabo/legam deja de emplearse, hay un matiz de menos en la gama de expresiones de la futuridad. O mejor: entre varias capas estilísticamente diferenciadas, la que usa el tipo dabo/legam queda reducida a la lengua escrita.

\section{Muerte del tipo dabo/legam}

Para explicar la desaparición, en el lenguaje hablado, del futuro sintético latino se han presentado motivos psicológicos, estilísticos, histórico-filosóficos, por un lado, causas fonéticas, por otro. En general, se suelen combinar las motivaciones de ambos lados, acentuándose, más o menos, la importancia de uno u otro. Así, al resumir la cuestión, Heinrich Kuen concluye que, al lado de la flaqueza fonética de las formas sintéticas, la ventaja psicológica de las perífrasis «no habrá sido sin importancia para el progreso de las formas analíticas» ${ }^{3}$. Pero es evidente que sólo una de las dos puede haber sido la causa original.

Thielmann fue el primero que atribuyó importancia decisiva, para. la muerte del tipo dabo/legam, a las causas fonéticas, es decir, a las

1 HofMLANN-SzANTYR, § I75; H.' LAUSBERG, Roman. Sprachwiss., § 837.

2 Gramm. der roman. Sprachen 2, § 112.

- Festgabc Gamillscheg, 1952, p. 145 ss. (frase citada: 158); cf. LAUSBERG, l. c. 
homofonias ya existentes en el paradigma verbal del latín literario y otras originadas en el latín vulgar ${ }^{1}$. Meyer-Lübke, al contrario, ve el origen del proceso en cuestión en las tendencias del lenguaje popular y su carácter afectivo: "Das Präsens an Stelle des Futurums ist wohl schon in lateinischer Zeit in der Volkssprache ganz gewöhnlich gewesen und hat mit am meisten dazu beigetragen, dass das alte b-jiuturum untergegangen ist" ${ }^{2}$. Más tarde, y sin corregirse, a pesar de la popularidad que el principio de la homonimia había adquirido entretanto, pormenoriza: "El románico ha olvidado completanente el futuro imperfecto latino, y no ciertamente por razones de forma, ya que, por lo menos, el futuro en -bo no coincidía con ningún otro tiempo, sino porque el modo de pensar popular refiere a la actualidad la acción futura, $o$, más precisamente, la concibe como algo querido o que hay que hacer; y así dice: volo, debeo, habeo cantare" ${ }^{3}$. Con interpretaciones de indole muy diversa, siguen este camino varios investigadores", sin convencer a otros que abogan por la explicación fonćtica de Thielmann, atribuyendo el mismo papel decisivo que tiene la homonimia en la sustitución de gallus por vicarius en gascón al de la "stustitución" del tipo dabo por las expresiones analíticas de futuridad ${ }^{5}$.

Intre los cuatro casos de homofonía aducidos por Thielmann, dos son irrefutables, los otros bastante problemáticos. El primero, la falta de distinción en los tipos legam/faciam audiam entre las primeras personas del futuro y del presente del subjuntivo, ya pertenece a la lengua clásica. A él se asocia, por la pronunciación igual de $\bar{c}$ e $\bar{i}$ finales en el lenguaje vulgar, la confusión fonética de legès, legêt fut. con legīs, legĭt presente del indic. que largamente identifica, en la $3 .^{2}$ y $4 .^{a}$ conjugación, los dos tiempos gramaticales. Pero es muy dudosa la posibilidad de una fusión del futuro amabis, amabimus/delebis, delebimus con el perfecto amavi, amavimus/delevi, delevimus, ya que las formas de perfecto deben haberse contraido (-ái; -ámus/ -ammus/-áumus) antes de realizarse el cambio de $-b->-v$ - en latin vulgar ${ }^{6}$. $Y$ hay que excluir, con seguridad,

\footnotetext{
1 Timelmann, pp. i 57-IG2; cf. Hofmann-SzantyR, p. 309.

2 Grammatik, 3, I899, p. II 7 s.

3 Inlroducción a la lingḯstica románica, 1926, p. 288.

- K. Vossler, Festschrift Philipp August Becker, 1922, p. I79; Ch. BALLY, Le langage et la vie, 1926, p. 73 S.; E. COSERU, Sincronla, diacronía e historia, I958, p. 89 ss. (con más bibliografía).

s MÜLIIR, nota I2; W. VON WARTBURG, Einführung', 1962, p. IOI ss.; B. E. Vidos, Manuale, 1959, p. 205.

- Accptan la fusión fonética de los dos tiempos propuesta por Thielmann: Holfmamn-Szantyr, von Wartburg, Vidos, Lausberg, Hüller...
} 
la idea de Thielmann, vuelta a tomar recientemente por Bodo Müller, que, para el norte de la Galoromania, se diese una confusión del futuro de la $x^{2}$ y $2 .^{a}$ conjugación (amabis, amabit/ delebis, delebit, etc.) con el imperfecto (amabas, amabat, etc.), por causa del cambio de $-a>-e$ en francés: "Es wird kaum beachtet, dass darüber hinaus im Norden der Galloromania in etwas späterer Zeit in den Verbklassen I und 2 bei den Personen 2 und 3 eine die Verwechslung der Tempora begünstigende Annäherung des Futurs an das Imperfekt erfolgt sein muss" 1. El descuido de esta idea de Thielmann está bien justificado: cuando el cambio $-a>-e$ se dio en la Galia septentrional, el futuro sintético latino había . muerto hacía ya siglos en el lenguaje hablado.

No se encuentra, por eso, $\tan$ kauf schwachen Füssen la argumentación de Meyer-Lübke, como Bodo Müller cree (48). El problema precisaria un nuevo examen.

\section{dare habeo y daraio}

- Lo que distingue la perifrasis latina dare habeo de las otras mencionadas es su evolución, en gran parte de los idiomas románicos, hacia una nueva forma sintética daré/darò/darei. "Entre los tiempos de creación romance», formula Menéndez Pidal, "sólo merecen examen los compuestos de infinitivo + presente o imperfecto indicativo de haber, por haberse verificado entre sus dos elementos una fusión más íntima que en los otros" 2. También este proceso es interpretado de diferente manera. Varios investigadores han querido separar rigurosamente la etapa allalítica de habeo dare y dare habeo de otra en que dare habeo se ha cristalizado en forma sintética darai (o). Esta no sería autóctona en todas las lenguas donde se encuentra arraigada, sino que habría irradiado desde un centro de cultura mucho después de la formación de la perífrasis.

La idea es de Meyer-Lübke, que ya en su Grammatik der romanischen Sprachen alude a la influencia de las lenguas literarias francesa y toscana en la difusión del tipo sintético $(2,138)$. Más tarde, el mismo autor matiza esta explicación: el deseo de dar expresión nítida, dentro del sistema

1 MÜLLER, 47; más vagamente: GRANDGenx, Introducción, p. 99.

2 Manual, § 123, I. Para lo que se discute aqui, importan menos las transiciones entre uforna analitica y forna sintétican; cf. MEYER-LUtBKI, Grammatik 3 , p. II7; J. HUBER, Altportugiesisches Elementarbuch, 1933, p. 205 (es muy dudoso "direi e non estar = 'direi e não estarei'; cf. Cancioneiro da Biblioteca Nacional, edición E. P. y J. P. MLACuADo, 5, 1956, p. 84 s.), 209 (gall.-port. ant. guardaria y guardar avia). 
verbal, al futuro, se habría impuesto primero en el sur de Francia, de donde la forma fija cantarat 'cantará' habría penetrado hacia el Norte y hacia Italia, sustituyéndose, a la vez, la forma separada vederloat 'lo verá' por vederatlo 1 .

Contra la crítica de Spitzer ${ }^{2}$, Rohlfs renovó esta interpretación modificándola en varios puntos: parte del hecho de que las primeras formas sintéticas se hallan en textos latinos del norte de la Galia y en los textos franceses más antiguos y de que sólo el románico del norte de Francia desconoce cualquier rasgo de las formas analiticas, al paso que la Italia central y septentrional, el sur de Francia y la Iberorromania conocen el tipo separable en tiempos medievales y en parte hasta hoy; así llega a la conclusión de que el norte de la Galia es el foco de la cristalización (ya realizada alli tal vez en el siglo vI) y de la expansión de la forma sintética: "Podemos seguir con bastante exactitud el camino que tomó el futuro sintético. Bastante temprano penetra hacia el sur de Francia, siguiendo el curso del Ródano, atraviesa los Pirineos en un período más tardío, pero sólo con atraso consigue sustituir la forma separable de los dos lados de la cordillera (siglo xIV). Muy debilitada ya, la ola llega al interior y al sur de la Península, más tarde todavía a la antigua Lusitania, donde la lucha entre darabeo y abco dare se desarrolla todavía ante nuestros ojos. Del otro laclo, el futuro sintético salido del norte de Francia, después de pasar por el M. Genèvre y el pequeño $S$. Bernardo, hace su entrada en el Piamonte y en la Toscana. Debido a la literatura floreciente, una nueva ola se expande en el siglo xim tanto hacia el Norte, hacia Lombardía, Venecia y los Alpes réticos, como hacia el Sur, a la Umbría, a Roma y a la Terra di Lavoro. Esta ola también continúa su marcha todavía hoy" ${ }^{3}$. Como se ve, el criterio de esta interpretación del futuro sintético como creación del norte de Francia y como innerromanisches Wandergut» en el resto de su área medieval y moderna es la cronología, ya de la documentación de las formas sintéticas, ja de la supervivencia de las formas separables.

Aceptando esta interpretación dinámica, Heinrich Kuen ha intentado apoyarla con dos argumentos morfológicos que, según él, predestinaron el latín del norte de la Galia a crear el nuevo futuro sintético:

\footnotetext{
1 ZfSL, I917, XLIV, p. 95; LEO JORDAN, Altfranz. Elementarbuch, I923, p. 227. nota.

Aufsätze, p. I73 ss.

- Arch. Rom., I922, VI, p. II3 (traducido). Gamillscheg, en lugar de uno, cree posibles dos focos de irradiación del nuevo futuro sintético: Francia del Norte e Italia Central ( $Z r P, 43$, p. 725).
} 
primero, porque sólo el francés antiguo, entre todas las lenguas románicas, conserva el futuro latino del verbo sustantivo (ero, eris, erit, erimus, erunt) y porque el empleo de un futuro sintético de este verbo frecuente podía influir, tanto en el tránsito semántico de la perifrasis modal cantare habeo al sentido futúrico cuanto en el tránsito de la forma perifrástica a forma flexiva uniforme e inseparable; segundo, porque sólo el francés empleaba las desinencias -ai, -as, $-a$ en [el singular de una conjugación de] otro tiempo sintético, el pretérito (perfecto latino) chantai, chantas, chanta, de manera que el sistema desinencial del pretérito pudo, asimismo, ejercer una influencia sobre la sintetización de los futuros ${ }^{1}$. La fórmula de Rohlfs y Kuen, repetida por Bodo Müller $(47,57,60,8 \mathrm{I}$ ), corresponde a un principio de explicación muy difundido hoy en la etimologia e historia de palabras de las lenguas románicas ${ }^{2}$; en el campo sintáctico, sigue una sugerencia de la Tempuslehre de Gamillscheg, de rgr3. Pero esta fórmula tiene graves defectos. Si una influencia tan profunda del francés (carolingio o poscarolingio) en la estructura sintética de otras lenguas románicas ya es poco probable en principio, en el caso del futuro sintético los argumentos cronológicos de Rollifs y los morfológicos de Kuen carecen de fuerza probatoria. El hecho de que los primeros ejemplos para el futuro sintético sean franceses, no significa nada para los origenes del sintagma, ya que este futuro está completamente desarrollado en otras lenguas románicas desde sus primeros documentos: en español, en italiano, en gallego-portugués ${ }^{3}$. En estas regiones la vitalidad, más o menos duradera, de las formas separables (hasta hoy día en portugués) no dice nada contra la antigüedad ni contra el carácter autóctono de sus formas sintéticas. $\mathrm{X}$ el querer relacionar la conservación de ero en francés antiguo y el paradigma francés chantai, chantas, chanta, con la sintetización del tipo cantare habeo es un fetichismo morfológico inaceptable. Toda una serie de razones nos obliga a abandonar la leyenda carolingia o francesa-poscarolingia.

Considerando la documentación antigua en las lenguas literarias mencionadas, no puede caber duda de que el latín lablado ya conocía las formas sintéticas al lado de las analíticas. Las condiciones de esta variación son de carácter sintáctico-rítmico e íntimamente ligadas con las condiciones de la posición de los pronombres átonos en latín vulgar.

1 Festgabe Gamillscheg, 1952, p. I59; cf. VrDos, p. 421.

- Cf. G. RorllFs, Feslgabe Gamillscheg, 1952, pp. III ss.

s R. MLenéndez Pidal, Cantar de mio Cid I, $\$ 99,205,7 ;$ los indices de E. Monacr, Crestomazia italiana: C. APPEL, Provenzalische Chrestomathie. Cf. MÜLLER, nota 85 . 
Tomemos como ejemplo bastante conservador el sistema del portugués de hoy:

(escribo): escrevo-te / não te escrevo / que te escrevo / quem te escreve?

(he cscrito): lenho-le-escrito / näo te tenho escrito / que te tenho cscrito / quem te tem escrito?

(cscribire): cscrever-le-hei / mio te escreverei / que le escreverei / qucm te escreverd?

Los ejemplos muestran claramente el mecanismo: la separación del futuro (y de otros tiempos "medio-analíticos") se da por la imposibilidad de colocar el pronombre átono al principio de la frase o de un grupo fónico; se emplea, empero, la forma sintética, cuando precede un elemento fuerte ( $n a \tilde{o}, q u e, q u e m)^{1}$. Las circunstancias son semejantes en todas las lenguas románicas que conocen o han conocido la coexistencia de formas analíticas y formas sintéticas del futuro con habeo ${ }^{2}$.

Cuando en estas lenguas se quiere evitar la forma analítica, separada, queda la posibilidad de acompañar el verbo por un pronombre sujeto o un adverbio. Así, en portugués cscreverte-ci alterna con cu te escreverci, com corlcza te cscrevcrci. Iil francés arcaico únicamente se distingue del portugués por haber renunciado a las formas separables, sin renunciar por lo demás a vedar la posición inicial al pronombre átono. El tipo español moderno $T e$ daré es tan imposible en el francés más antiguo como en otras lenguas románicas medievales. Doy como prueba los cinco ejemplos que ofrece La vie de Saint Alexis para futuros acompañados de pronombre átono:

Se a mei te voels tenir

Si t'guarderai pur amur Alexis (3I, I-2).

S'or me conuissent mi parent d'(ic)este terre,

Il me prendrunt... (4r, 3-4).

Por amor deu e pur mun chier ami,

Tut te durai, boens hom, quanque m'as quis (45).

An la maisun Eufemien quereiz!

Quer iloec est, iloec le trovereiz. (63).

Lai li la cliartre, par la tue mercit, So nos dirrat qu'enz troverat escrit (74).

1 J. Duns, A Grammar of the Portuguese Language, 1930, §§ 246 ss., p. 274. Para cl español del siglo xvi: Hayward Kensiston, The Syntax of Castilian Prose, I937, pp. 89 ss.

2 H. IRAMSDEN, Weak-Pronoun Position in the Early Romance Langt!ages, I963. passim. Cf. W.-D. STEMPEL, Untersuchungen zur Satzverknüpfung in Allfranzösischen, 1964, Pp. 3 I $_{4}$ ss. 
No se puede, por lo tanto, hablar de un futuro sintético francés (carolingio) que hubiera irradiado a otras regiones de la Romania.

Hay, además, una razón elemental que confirma la continuidad del tipo daraio del latín vulgar y su carácter autóctono también fuera de Francia, que son las numerosas formas contractas del tipo it. verròl fr. vendrai-vicndrai / cat. vindré/ esp. vendré/port. ant. verrei, o it. potrò /fr. pourrai /esp. podré, etc. Ellas no se explican sino como heredadas, en los diferentes idiomas, directamente del latín: «Die Juxtaposition cantare habeo geht eine Worteinigung ein noch zur Zeit der Gültigkeit der lateinischen Quantitäten" ${ }^{1}$. Lo mismo vale para la evolución de las desinencias del futuro románico (y del condicional). Esta explicación, naturalmente, no excluye la presión que ciertas lenguas literarias pueden ejercer sobre sus dialectos en favor del empleo de las formas sintéticas, cuando estas formas no pertenecen al patrimonio.latino del dialecto o tienen menor vitalidad en él.

Hemos vuelto aquí a la opinión de Leo Spitzer, expresada antes de aparecer la fórmula de Rohlfs-Kuen-Müller: "Nach meiner Anschauung ist also das cantaraio-Iiutur nicht innerromanisches Wandergut, sondern eine an verschiedenen Punkten der Westromania aus einem gemeinsamen vulgärlateinischen Ansatz entwickelte autochthone Bildung” 2. Pero si Spitzer continúa hablando de "gemeinsame Neubildungen wie das neuromanische Futurum" y de "ein gewisser Entwicklungskeim... der, auch bei Intwivicklung der einzelnen Sprachindividuen unter verschiedenen Bedingungen, ein gleichgerichtetes Wachstum zeitigt», parece necesario intentar separar menos vagamente la herencia latina de las evoluciones particulares realizadas en cada lengua románica. Aquí sólo se pueden dar unas pocas indicaciones.

En el área románica del futuro con habeo acabamos de encontrar diversas combinaciones: $1 .^{\circ}$ no te escribiré: escribir-te-he; $2 .^{\circ}$ no te escribiré: yo te escribiré (no te escribiré: escribiréle); $30^{\circ}$ no te escribiré: te escribiré. La primcra (coexistencia de formas sintéticas y analiticas; el complemento pronominal átono no puede ocupar el principio del grupo fónico), que se encuentra en varias lenguas medievales y en portugués moderno, seguramente ya existió en el latín hablado. La segunda (sólo se emplean formas sintéticas; el pronombre átono no aparece al principio de la frase), posible en cl área entera, es probable que también ya se usara en latín vulgar, constituyendo otro tipo estilistico ( $\mathrm{y}$ más tarde, regionalmente, el tipo único); lo mismo valdrá para la combinación no te escribiré: es-

1 Lausberg, $\$ 346$; cf. MIEYer-Lubke, ZfSL XIIV, p. 96.

2 Aufsätze, p. 176 . 
cribiréte, de difusión geográfica menor antiguamente y hoy forma "poética» o "retórica» en varios idiomas del tipo tercero. Para la tercera, finalmente, que aparece tarde en los textos y hoy es usual en italiano, provenzal, catalán y español, importará averiguar si es formación individual en estas lenguas o si ticne raíces más hondas de lo que parece según la fecha de su aparición en los documentos escritos ${ }^{1}$.

Como se ve por cste esbozo, no se trata, con toda probabilidad, en el latín vulgar, de "cierto germen de evolución", del cual se habrian desarrollado, paralela e independientemente, las construcciones de los idiomas románicos medievales y modernos, sino de plantas ya crecidas e individualizadas en latín, entre las cuales las diferentes regiones románicas, más tarde, seleccionan cada una a su manera.

Insisto en el carácter incompleto de las consideraciones precedentesr La evasión de las formas separables, por ejemplo, que vimos conquistala mayor parte de los idiomas románicos en cuestión, penetra hasta dentro del gallego-portugués y se pucde valer aquí de un medio peculiar. Iin el gallego-portugués, como es sabido, hei de cantar y cantarei gozan de scmejantes derechos para expresar la futuridad. Así, evitando la forma separada (escrever-te-ci), se puede emplear ya el pronombre su. jeto (eu te escreverci), ya la construcción con haver de (hei-te de escrever). Iin los cuentos populares gallegos del partido judicial de Viana do Bolo publicados por Laureano Prieto ${ }^{2}$, aparece esta últina forma cuando el portugués, digamos normal, recurrirá a la forma separada:

Neste último hanse de estar bañando, p. 57 (= port. estar-se-äo banhando).

E mañia haslle de levar, 58 (levá-lo-ás).

Cuando llo dias hache de perguntar, 58 (perguntar-te-á)

i hanos de tapar, 6o (tapar-nos-á).

Nira, heiche de regalar esta burriña, 67 (regalar-fe-ei).

Cuando pensen..., hanche de vir a arroubar o pano, 70 (vir-te-ão).

Iu, se me pagáis ben, heivos gobernar a fonte, 47 (= habzo dare, port. governarvos-ei).

2 ROIIJ,E, Arch. Rom. 6, p. I2I S. (§ I4); V. BLiRTOLdI, La parola, I946, p. 259 ; IIUBER, p. 205.

2 Contos vianeses, Vigo, 1958. No aparecen en es:c texto los dos otros tipos meucionados por V. GARcí DE DUGG, Elementos de gram. hist. gallega, 1909, p. 13I: I. volo pagarä, $20^{\circ}$ achará'o. İl segundo es bastante corriente (cP. ANXEL -I.or.l, Terra Brava, Ld. Galaxia, s. a.: "Cada noite contareiche un conto ...., p. 3r; "Deiqui a poucos anos retirareine., p. 32; "Agardareite no horto", p. 36); para cl primero, no he encontrado ejemplos al principio de la frase o del grupo fónico. 
Podríamos así establecer otro tipo de combinación: non te escreverei: hei-te de escrever, del cual no sabemos ni la expansión ni la historia ${ }^{1}$. Valdrá la pena abrir más caminos por un terreno poco explorado.

\section{¿Evolución repctida o tradicion?}

Al tratar del presente de futuridad, Meyer-Lübke hace una comparación entre el latín y los idiomas románicos: si el praesens pro futuro, corriente en el lenguaje popular latino, ha contribuido decisivamente, según él, a la supresión del futuro sintético dabo, etc., este proceso "parece repetirse" en la Romania actual, porque el presente de futuridad, limitado en las lenguas literarias a la expresión afectiva, juega un papel mucho más importante en los dialectos ${ }^{2}$. A la competencia del presente de futuridad se asocia la de las perifrasis. Ya en I9r3, Gamillscheg pronostica para el francés: "Das Französische ist auf dem Wege, seinorganisches. Futurum zu verlieren und dafür Unschreibungen eintreten zu lassen. Die Schriftsprache hat die Fornel je vais venir als sogenanntes unmittelbares oder nälieres Futur übernonmen; die Umgangssprache verwendet aber $j c$ vais venir, bzw. je dois venir ganz allgemein für das untergehende Futurumn ${ }^{3}$. La repetición, en nuestros dias, de un proceso histórico realizado hace unos dos mil años parece obvia: wLe latin vulgaire remplace cette forme (intrabo) par intrare habeo... [transformś] dans la forme entièrement suffixale du futur français en -ai ( $j^{\prime}$ entrerai)... Mais voici qu'à son tour ce futur est battu en brèche; il est insuffisant pour les besoins de l'expression affective, et plusieurs formes périphrastiques aspirent à lui succéder ( $j$ e vais entrer, je veux entrer, et, provincialement: il veut pletvoir; il doit venir à cinq heures); aucune n'a triomphé définitivement)" 4 .

Son voces de esta indole las que han afectado gravemente a Bodo Müller y le han llevado a pintarnos, en la segunda parte de su trabajo citado, un cuadro colorido de la agonía del "Altfutur» románico (darò) daré(donnerai...), y del inexorable progreso de los "neofuturos» anali-

1 Sobre el posible motivo sintáctico-ritmico de la variación demane aio canttare: aio ie cantare: cantaraio, cf. GAMmLSCImG, $Z r P, 43,725$. En los textos gallegos mencionados, encontramos estos tipos, pero también los coutrarios (demane aio de cantare; aio cantare; demane caintaraio); véanse las frases arriba citadas, y además: "Salirá el i eutrará o outrow; "Ha de ser todo como tu queresu; "Has de traer dous pcleros».

- Grammatik, 3, p. Ir8.

- Tempuslehre, 302; L. JORDAN, p. 180.

- BAIry, p. 73 s. 
ticos modernos. En cuanto al francés, se apnya en frases como "Le futur traverse une crise en langage populaire" (Henri Bauche) o "Dans la langue de la conversation le futur périphrastique tend à remplacer le futur" (Paul Imbs), y no faltan juicios semcjantes para las lenguas hernanas. Como por un destino dichoso o un acaso prodigioso, la filología histórica de nuestro siglo parece haber nacido en buena hora para ser testigo ocular del dramático proceso de la "Futurneubildung" (54), "Fiturerneuerung" (90 s., 93 s.), del "Aufbau von Neufuturen" o "Neuaufbau des Futurs" $(88,90)$, de la "Neubildung eines Futurs» (88) o de la «im Gang befindliche Abhalfterung von je chanterai, span. cantaré durch neue Periphrasen" (92).

Pero hará falta que el lector se desilusione. Es verdad que pasa mucho hoy día, pero con las expresiones de futuridad románicas no pasa lo dramático y grave que los autores citados ven, sencillamente porque su visión es fruto de un espejismo metodológico y de un error de perspectiva histórica. $\mathrm{Y}$ vamos a ver el porqué.

Si el latín (o los latines) disponen de una gama (o de gamas) respetables de expresiones de la futuridad, y si dispone de tal gama cada uno de los idiomas románicos, sería poco razonable suponer que no fuese asi en toda la cadena de generaciones latino-románicas descle César hasta De Gaulle, Franco y Salazar. Es verdad que, para gran parte del camino histórico, vemos poco claro cuál habrá sido, en las diferentes regiones, esta gama de expresiones. Pero esto no puede significar que tal variedad haya abdicado en alguna lengua o época y cedido el terreno a un "Normalfutur" (85, 9I) o a "das herkömmliche synthetische Futur" (89). Hay "cl futuro" de las gramáticas tradicionales que ha sido y sigue siendo una expresión de futuro frecuente, hasta preponderante en ciertas capas estilísticas del idioma y en ciertos contextos, y como tal puede llamarse "normal" dentro de los límites de este recinto estilístico-semántico; en otros, otras formas han sido y son más frecuentes, si se quiere "normales". El problema, como cualquier cuestión de sintaxis, es un problema estilístico en primer lugar.

La lectura de una parte de los Cuentos vianeses mencionados nos ofrece el siguiente orden de frecuencia de expresiones de futuridad enpleadas: hei de dar (I8 casos), darei (×3), vou dar (9), vou a dar (5), hci dar (4); raras: dou, venho dar, venho a dar, estou por dar, vou e dou, y otras; cs escaso, en estos textos, el empleo no futúrico de estas expresiones (fuera de dou, y vou + inf.). Al contrario, un texto portugués moderno nos presenta: vou dar (8), hei-de dar (3), darei (2), estou para dar (I), al lado de un uso frecuente de darei dubitativo, de suposición (I2 casos) ${ }^{1}$.

1 LUIS DE STrAU MIONTEIRo, Angústia para o jantar, Lisboa ( $\left.{ }^{3} 1963\right)$, p. 50-78. 
Hacen falta análisis más extensos de esta índole que preparen el campo adecuadamente para el estudio histórico de la cuestión. Por ahora, ya son posibles algunas observaciones provisionales sobre las expresiones simples o perifrásticas de mayor frecuencia y difusión.

Como Meyer-L,übke, duda Bodo Müller si el presente de futuridad en dialectos cspañoles e hispanoamcricanos [y en el lenguaje corriente] es la continuación del praesens pro futuro latino o si él unicht bloss einem Neugebrauch entspringt (6I)" ${ }^{1}$. La duda es innecesaria, porque, como en latin, el empleo del presente de futuridad también en románico es ude todas las épocas" y por eso dentro de una tradición latino-románica ininterrumpida. Naturalmente, hay diferencias regionales, cronológicas, estilísticas en cuanto al recurso más o menos fácil a esta expresión, pero estas fluctuaciones se refieren a su historia en los diferentes ambientes lingüisticos, no a su origen. (Y no hará falta mencionar que, cuando decimos "tradición" = "no innovación" argumentando en el plano de la (langue», siempre significa "renovación" en el plano de la "parole».)

Lo mismo vale para la colaboración que, en la expresión de la futuridad, prestan en francés devoir, vouloir y aller, colaboración que ya prestaron sus predecesores latinos y medievales 2 . Como no podemos conocer la extensión de estas cxpresiones de futuridad en el habla de épocas pasadas, tampoco es lícito concluir, con Gamillscheg y Müller ( $84 \mathrm{~s}$ )), que ellas, y sobre todo aller, hayan ampliado progresivamente su papel y llegado a ser, hoy, un "ernsthafter Konkurrent des Normalfuturs" ${ }^{3}$. $J c$ vais parler siempre ha sido una seria colaboradora de je parlerai (y de otras) cn la evocación de lo futuro, con matices semánticos individuales, y el hecho de que aparezca más ell ciertos gémeros literarios modernos es un fenómeno de historia literaria más bien que de la historia lingüística de estas formas. Las profundas raíces y la importancia ya antigua de vado (ad) + inf. las evidencian, fuera de los textos, su larga difusión geográfica y su amplio empleo en otras regiones de la Romania. Para el portugués, Müller desconoce el enorme prestigio del tipo vou dar en el

1 De manera semejante, MIEYER-LÜBKE pregunta cuanto al futuro de necesidad, nob tí irás in siune von 'du musst gehen' den letzteu rest des lateinischen habes ire enthalte oder sich erst aus 'du wirst gehen' entwickelt habe. Lerch spricht sich für das letztere aus und es unterliegt gar keinem zweifel, dass er recht haben kanw, es ist aber auch ebenso gut möglich, dass beide anwendungen frühzeitig oder so zu sagen von anfang an neben einander gestanden haben» (RLiR, r, 1925. p. I7 s.). También en este caso sólo cabe aceptar la continuidad.

2 Cf. páng. 03, nota 1; GrandGent, Introducción, § 126, 3-5; Mür,IIR, p. 64 s.

3 L. Flydal, aller et veuir de, 1943, p. 47 y passim; G. Gouglnimim, Eitude sur les púpiphrases vorbales de la langue frangaise, 1929, I, cap. II y III, p. 66 ss., 85 ss. 
lenguaje coloquial 1: es la expresión verbal de futuridad más usual o. de las más usuales, tanto en Galicia como en Portugal y el Brasil, en la conversación corriente. $\mathrm{Y}$ como el caso es semejante en provenzal, no hay motivo para suponer influencias francesas en el sur de Francia $\left(S_{7} \mathrm{n}\right.$. IOS) o influjo provenzal en el francés (85), o de declarar como galicismo (nota (08), sin estuclio previo, la aparición de vado (ad) + inf. en Italia. ial que el tipo voy a hacer (voy haccr) predomine, para la expresión de la futuridad, en dialectos judeoespañoles, asturianos y leoneses asi como en el habla español e hispanoamericano corriente testimonia la antigüedad y el carácter intrinsecamente coloquial de este sintagma, pero no su ascendencia progresiva "auf Grund gemeinsamer Ansätze» (86, cp. 87). - El párrafo que Bodo Müller dedica al tipo haber de + inf. provoca y exige una crítica idéntica: "Namentlich in Amerika hat sich die Formel habeo de + inf., die im Mutterland schon im II. Jalirhundert zur Umschreibung des Futurums gelangt war [Rohlfs], zu einer temporalen IFormel entwickelt; sie hat dort im Zusammenwirken mit ir a + inf. und mit dem futurischen Präsens das herkömmliche synthetische Iiutur (cantaré, cantarás, etc.) aus der Umgangssprache nahezu verdrängt... Ganz parallel ist dic Iintwicklung auf den Philippinen verlaufen..." (88 s.). No hay "evolución" o "evolución paralela» entre Iispaña e Hispanoamérica o entre estos territorios y las Filipinas, sino una preferencia inveterada común, en el lenguaje corriente de las tres regiones de habla española, para haber de + inf. como expresión ya de la necesidad, ya de 1a futuridad. En los paises hispanohablantes extra-curopeos, es uno de tantos rasgos más bien arcaizantes, que asenejan su español al de los dialectos del noroeste de España y a usos del gallego-portugués. La existencia europea de este sintagna fuera de la Peninsula Ibérica hace entrever su formación y difusión ya en época latina ${ }^{2}$.

He insistido aqui en dos principios: el de la pluralidad de las expresiones futúricas durante toda la evolución latino-románica; y el de la antigüedad y continuidad de las expresiones románicas más importantes

1 "Im portugiesischen Sprachbereich scheint der vado-Ersatz in Galizischen aufzutreten" (86); es arbitraria la conclusión: "... dass das Portugiesische, das ja über den Typus hei de cantar verfügt, kaum eines Neufuturs bedarf" (94).

2 Desde MEYER-LüBke (v. p. 65, mota 2), las formas preposicionales (habeo de, habeo ad) se suelen considerar como de fecha posterior: Ronnfs, Arch. Rom. $\sigma$ I 5 ("viel jünger"); cf. GMMULLSCIIEG, $\operatorname{ZrP}, 43,723,726$; MÜLLER, 82. En todo caso, no hay para qué dudar de su origen ya latino ni de su difusión en las provincias del Imperio Romano, cvidentemente con funciones varias (necesidad, futuridad, suposición...). Supone un origen relativamente tardio (y griego), hasta para habeo cantare, M. LEUMinNN: "Damit und nach der Art der Zeugnisse verbietet sich auch 
en este sector. Bodo Müller, 'que ve y respeta teóricamente estos principios (54), ha dejado de aplicarlos y seguido modelos incompatibles con ellos. Así, el simple concepto de "futuro normal» le lleva automáticamente a aislar otra vez el futuro de entre las expresiones de futuridad, y a aquel famoso esquema de evolución lineal: del presente de futuridad *cantablu al sintético cantabo, "sustituido" por el analítico cantare habeo sintetizado de nuevo en je chanterai, forma otra vez abandonada por la composición de presente je vais chanter; quiere decir a la concepción del "fortführenden Kreislauf des Entwicklungsprozesses", del continuo movimiento circular de la evolución que ha sido una idea preferida en la filología de principios de nuestro siglo.

No. La historia de la lengua es un fenómeno histórico y no un proceso de evolución ${ }^{1}$. Donde nuestro autor ve cinco etapas sucesivas, hay en el fondo una tradición y continuidad vivas (de variados sintagmas de futuridad) con una sola escisión fuertemente marcada: la pérdida del tipo dabo/legam, parte del "gran naufragio de las formas gramaticales latinas" (Diez) que se debe a una crisis histórica incomparable a ninguna otra, y única" en la historia europea (Jacob Burckhardt). La crisis descrita por Gamillscheg, Bally, Müller, con la muerte prevista del futuro románico darò/donnzerai/daré es una profecía que puede realizarse dentro de poco, o dentro de siglos, o, por decirlo así, ununca». No sabemos los naufragios reservados en to Futuro a la parte románica de la humanidad.

Como no hay Kreislauf, tampoco hay Wettlauf. Según el progreso a que habrían llegado en la carrera hacia la supuesta renovación del futuro, Müller establece un orden entre algunos idiomas románicos modernos: francés, español, catalán, italiano. Es un orden arbitrario, y no son pertinentes los argumentos con que intenta justificarlo:

el que el francés sería el primer idioma en que la forma sintética

die seit Thielmann (5r-57 passim) allgemein angenommene Vermutung, die Infinitivkonstruktion habe trotz ihres Fehlens bei Plautus der Volkssprache angehört und Cicero habe sie aus dieser überuommen. So sehe ich als einzige Erklärungsmöglichkeit die Anmahme eines Graezismus, einer Ubernahme aus dem Griechischen, also einer Lehnübersetzung" (MIuseum Helveticum, 1962, XIX, p. 69). Según Thielmann, la construcción de inf. + habere con sentido futúrico nació en la literatura teológica de los padres africanos y con ella irradio hacia Galia e Italia (THIELMANN, 182).

1 Las explicaciones histórico-filosófica o histórico-religiosa de Vossler y Coseriu, absolutamente legitimas en principio, carecen todavia de una fundannentación más coucreta y amplia. No es admisible la critica metodológica que coutra ellas dirige MUULIIER (por ejeiuplo: "Vossler ging in dem Augenblick zu weit, als er die gruppenpsychologische Erklärung zu einer kulturhistorischen ausweitete, statt sie zu einer allgemeinpsychologischen zu erhebeun, l. c., 50; cf. KUEN, 157 s.). 
chanterai vio la luz $\mathrm{y}$, por lo tanto, predestinado a ser el primero en que desaparezca;

el que la coexistencia de ho, hai, ha y canterò, canterai, canterà en italiano, de he, has, ha y cantaré, cantarás, cantará en español (frente a j'ai, lu as, il a, con sujeto pronominal, en francés) habria contribuido a manteuer mejor el futuro sintético en las dos primeras lenguas;

el que en español y portugués la existencia de he de/hei de ejercería un influjo conservador semejante;

el que en castellano y catalán la reducción de haber/haver a verbo auxiliar haya debilitado el futuro sintético formado con este verbo, al contrario de lo que pasa en italiano, donde avere se conserva en plena función;

el que el francés $j e$ vais chanter haya surgido como competidor de $j e$ chantera $i$ en la misma medida en que $j^{\prime} a i$ chanté ha desplazado a je chantai...

Todas estas combinaciones artificiales denotan elementos de causalismo y superstición inorfológicos, debidos tal vez, en parte, al contagio de un estructuralismo juguetón, de bajo precio.

Firente a estas tentativas, propongo otra vez el camino ya recomedado: cuando se hagan estudios sobre las expresiones de futuridad en textos de las cuatro lenguas románicas mencionadas (y otras), se verá la enorme variación que, según el ambiente lingǘstico y contexto de que se trate, se presenta en cada una, también relativo a la frecuencia del futuro sintético. Posiblemente, para la vitalidad del futuro romance, se distinguen menos las lenguas entre sí que los climas estilísticos de que ellas disponen. En el lenguaje hablado familiar nunca habrá jugado el papel de protagonista dentro del elenco de las expresiones de la futuridad.

HARRI MIEIER. 